\title{
Drugs for the Prevention and Treatment of Cardiac Allograft Vasculopathy
}

\section{Shuchita Gupta MD*}

Thomas Jefferson University Hospital, Philadelphia, PA, USA

\begin{abstract}
Cardiac allograft vasculopathy (CAV) of heart transplants is responsible for up to one-third of deaths at 5 years following cardiac transplantation. Risk factors for CAV include both traditional risk factors and immune factors. Drugs used for prevention and treatment of CAV include statins, calcium channel blockers and immunosuppressive agents. This review discusses the currently available drugs for CAV, the evidence behind their use, and future targets of therapy.
\end{abstract}

Keywords: Cardiac allograft vasculopathy; Cardiac transplantation; T-cells; Statins

\section{Introduction}

Cardiac allograft vasculopathy (CAV) is a specific form of coronary artery disease that affects heart transplanted patients and is characterized by an early, diffuse intimal proliferation of both the epicardial and microvascular vessels, resulting in epicardial coronary artery stenosis and small vessel occlusion [1]. Intimal hyperplasia and infiltration of inflammatory cells are confined to the graft vasculature, with sparing of the recipient's own arteries, suggesting an immunemediated local process.

According to the $29^{\text {th }}$ Official Adult Heart Transplant Report, CAV affects $8 \%$ of heart transplant recipients by year $1,30 \%$ by year 5 and $50 \%$ by year 10 after the transplant [2]. Once CAV develops, treatment is challenging and often frustrating; therefore strategies to prevent its development need to be implemented right from the time of cardiac transplantation. This article provides an overview of the various drugs available for prevention and treatment of CAV, the evidence behind their use, and clinical framework for their use.

\section{Risk Factors and Pathophysiology of CAV}

Risk factors for CAV include both traditional risk factors such as hyperlipidemia (exacerbated by calcineurin inhibitors), hypertension and diabetes mellitus (worsened by steroids), transplant-related factors such as donor factors (explosive mode of brain death, intracranial hemorrhage), and immune factors. The latter include increased levels of cytotoxic B-cell antibodies, anti-human leukocyte antigen (HLA) antibodies, expression of non-HLA antibodies such as anti-vimentin antibodies, more acute cellular and humoral (antibody-mediated) rejection, cytomegalovirus (CMV) infection, and sensitization to the monoclonal antibody OKT3 $[3,4]$.

Brain death itself induces an immune response. After brain death, neurohumoral and molecular changes result in cellular stress and an inflammatory response, this induces the expression of endotheliumderived major histocompatibility complex (MHC) molecules and costimulatory signals [5].

Alloimmune injury is initiated when donor MHC antigens expressed on the surface of graft endothelial cells interact with recipient dendritic cells, resulting in a chronic immune response. Recipient $\mathrm{CD} 4^{+} \mathrm{T}$ lymphocytes recognize donor MHC class II antigens on the cell's surface (HLA-DR, DP and DQ) and are activated, leading to a cascade of cytokines that further stimulate the donor endothelial cells to secrete growth and chemotactic factors [6]. These factors recruit mononuclear cells, which then secrete cytokines that activate normally quiescent vascular smooth muscle cells (VSMCs). These VSMCs then transform from contractile cells to de-differentiated synthetic cells. Activated VSMCs migrate from the media to the intima of endothelial cells, where they proliferate and cause extracellular matrix deposition, leading to reduction in the luminal diameter and loss of vascular contractility, (Figure 1). This process is responsible for most of the obliterate arterial intimal thickening present in CAV, and occurs diffusely [7].

Due to the predominant role of immunologic factors, CAV was long regarded as a form of chronic rejection. However, evidence of significant contribution of other metabolic factors to the development of CAV has led to the "response to injury" concept, according to which chronic endothelial injury from a combination of immune and non-immune factors leads to vascular cell proliferation, fibrosis, and vascular remodeling [8]. Recent evidence based on virtual histology intravascular ultrasound (VH-IVUS) suggests that ischemic etiology of cardiomyopathy prior to heart transplant may be independently associated with development and progression of plaques and higher cardiac event rate after transplant, highlighting the contribution of atherosclerosis to the pathogenesis of CAV [9]. In this study, VH-IVUS performed on 2 separate occasions after transplant revealed that patients with ischemic cardiomyopathy had significantly higher necrotic core, dense calcium, and fibrous and borderline high fibrofatty components in the plaques, similar to vulnerable plaques in atherosclerotic coronary artery disease.

The immune and inflammatory mediated endothelial injury also leads to endothelial function [10]. Using serial studies with Doppler flow-wire measurements, decrements in coronary endothelial function have been demonstrated to be associated with progressive intimal thickening and subsequent CAV development [11].

Even though the mechanisms of CAV and atherosclerotic coronary

*Corresponding author: Shuchita Gupta MD, Jefferson Heart Institute, Thomas Jefferson University, 925 Chestnut Street, Suite 323A, Philadelphia, PA19107,USA Tel: 215-955-2050; Fax:215-503-0052; E-mail: shuchita1980@yahoo.com

Received: September 29, 2014; Accepted: October 28, 2014; Published: October 31, 2014

Citation: Shuchita Gupta MD (2014) Drugs for the Prevention and Treatment of Cardiac Allograft Vasculopathy. Cardiol Pharmacol 3: 123. doi:10.4172/23296607.1000123

Copyright: (c) 2014 Shuchita Gupta MD. This is an open-access article distributed under the terms of the Creative Commons Attribution License, which permits unrestricted use, distribution, and reproduction in any medium, provided the original author and source are credited. 
artery disease (CAD) were initially considered to be completely different,recent research has narrowed the difference between the two. While both atherosclerotic CAD and CAV are driven by adaptive immune responses to antigen, the antigens are different. The principal antigens driving atherosclerosis are altered (oxidized) low-density lipoproteins that are taken up by macrophages that become foam cells [12], whereas the principal antigens in the case of CAV are non-self MHC molecules, especially HLA-DR, expressed most abundantly on the luminal endothelial cells [13].

\section{Pathological manifestations and diagnosis of CAV}

CAV manifests as diffuse intimal hyperplasia with progressive luminal narrowing. The expanded intima comprises smooth muscle cells (SMCs), microvessels and an infiltrate formed largely of host $\mathrm{T}$ cells and macrophages, the majority of $\mathrm{T}$ cells being memory cells that express interferon- $\gamma$ (IFN- $\gamma)$ and transforming growth factor- $\beta$ (TGF- $\beta$ ) [14]. The SMCs are mostly graft-derived, but recipientderived SMCs are also found as a result of seeding of graft vessels by recipient endothelial precursor cells that subsequently differentiate in to SMCs [15]. Nodular aggregates of host B cells, T cells, and myeloid cells are found in the adventitia, but the media is unaffected.

The diffuse nature of CAV makes it harder to diagnose it by coronary angiography, particularly in earlier stages. On angiography, observed luminal narrowing is compared to a reference vessel diameter for detection of significant stenosis. However, there is vascular remodeling with compensatory enlargement of the coronary vessel in the presence of a plaque, early in CAV development. Only in the advanced stages of CAV does luminal narrowing occur, making angiographic detection possible. Intravascular ultrasound (IVUS) is able to detect the extent of intimal thickening by imaging the vessel wall structure (including the presence and nature of the plaque) instead of relying simply on the diameter of the lumen, making it a sensitive tool for the early identification and diagnosis of CAV[16]. In a multicenter IVUS study, progression of intimal thickening of 0.5 $\mathrm{mm}$ or more in the first year after cardiac transplantation was found to be a reliable surrogate marker for subsequent mortality, nonfatal major adverse cardiac events, and development of angiographic CAV through 5 years after transplant[17].

\section{Drugs for the prevention and treatment of CAV}

\section{Calcium channel blockers}

One of the first reported drugs for prevention of CAV included calcium channel blockers (CCB) such as diltiazem. In one of the earliest studies, 106 consecutive heart transplant recipients were randomized to receive either diltiazem $(n=52)$ or no CCB $(n=54)$. On follow-up coronary angiography, the average change in the diameter of coronary artery segments at the end of two years differed significantly between the two treatment groups $(\mathrm{P}<0.001)$, even after adjustment for other relevant clinical variables. New angiographic evidence of CAV developed in 14 patients not given CCB, as compared with 5 diltiazemtreated patients. Significant coronary stenoses $(>50 \%$ luminal diameter) developed in fewer patients given diltiazem; death due to CAV or re-transplantation occurred in five patients in the group that did not receive CCB and in none of those who received diltiazem[18]. At 5-year follow-up, a significant difference was noted in freedom from both death and angiographic CAV (56\% in the diltiazem group versus $30 \%$ in the control group)[19]. However, a major limitation of this study was the use of angiography, for the reasons described above. In an intravascular ultrasound (IVUS) study of 32 patients by
Mehra et al. [20], treatment of cardiac transplant recipients with either angiotensin-converting enzyme inhibitors or CCBs was associated with a decrease in the degree of vascular intimal hyperplasia at 1 year after transplantation.

In vitro studies have tried to elucidate the mechanism of action of CCBs in reducing CAV. Diltiazem was shown to enhance the effect of IL-1 beta and reduce IL- 6 production in mixed lymphocyte cultures [21]. Thus diltiazem modulates monokine production and may affect antigen expression, thereby decreasing immune-mediated intimal hyperplasia.

After the initial large studies in the 1990s, not much research has been done in the use of CCBs for prevention of CAV. Nevertheless, diltiazem is relatively well tolerated, and has additional antihypertensive properties; therefore it continues to be used widely.

\section{Statins}

Statins inhibit HMG-CoA reductase, the enzyme that catalyzes the conversion of 3-hydroxy-3-methylglutaryl-CoA to mevalonate, and thereby also reduce the downstream products of mevalonate in the cholesterol synthesis pathway. The downstream products, farnesyl pyrophosphate and geranyl pyrophosphate, are lipid moieties that can modulate the function of certain essential signaling proteins that influence smooth muscle cells and the generation of nitric oxide (NO) [22]. Statins reduce matrix metalloproteinase secretion and SMC migration and proliferation, and the effect on SMCs may be the major mechanism by which statins decrease the development of CAV [23,24]. Statins also block activation of T-cells and natural killer (NK) cells by repressing interferon-gamma induced MHC-II expression [25].

In a study of cardiac transplant recipients randomized to pravastatin (47 patients) versus no pravastatin (50 patients), at 12 months, the pravastatin group had significantly lower mean cholesterol levels than the control group, less frequent hemodynamically significant allograft rejections ( 3 vs. 14 patients, $\mathrm{p}=0.005)$, better survival $(94 \%$ vs. $78 \%, \mathrm{p}=0.025$ ) and lower incidence of transplant vasculopathy on angiography or autopsy (3 vs. 10 patients). In a subgroup of patients, the cytotoxicity of natural killer cells was significantly lower in the pravastatin group compared to the control group [26]. In a serial intravascular ultrasound (IVUS) study performed in 93 transplant recipients, although conventional atherosclerosis risk factors did not affect the development of CAV, greater change in serum LDL cholesterol level during the first year after transplant wasassociated with more severe vasculopathy, thus indicating the benefits of treating all cardiac transplant patients with statins [27]. Subsequently, the benefit of pravastatin in reducing CAV was demonstrated even at 5 years (Figure 2) [28].

Aprospective, randomized, unmasked study initiated in 1991 compared the efficacy of simvastatin, started on the fourth postoperative day $(n=35)$, with that of dietary therapy alone $(n=37)$. At 4 years, significantly reduced low-density lipoprotein (LDL) cholesterol, improved survival and reduced incidence of CAV were seen [29]. After 4 years, patients in both groups received statins as open-label prescriptions. After 8 years, the Kaplan-Meier survival rate was $88.6 \%$ in the simvastatin group versus $59.5 \%$ in the control group $(\mathrm{P}<0.006)[30]$.

Subsequently, in a 12-month observational study comparing pravastatin $40 \mathrm{mg}$ with simvastatin $20 \mathrm{mg}$ after heart transplantation, rhabdomyolysis or myositis occurred only in patients on simvastatin, with no episodes for patients on pravastatin, despite similar reductions 


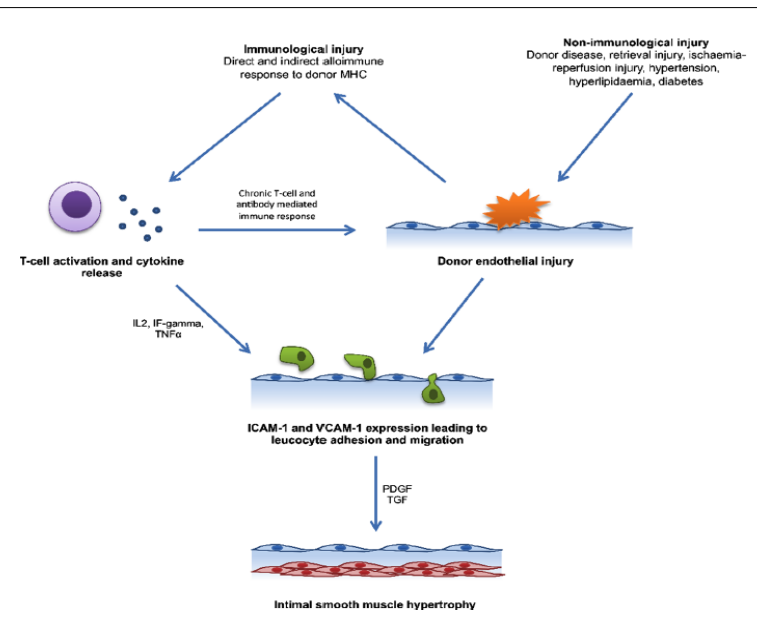

Figure 1: Mechanisms of cardiac allograft vasculopathy.

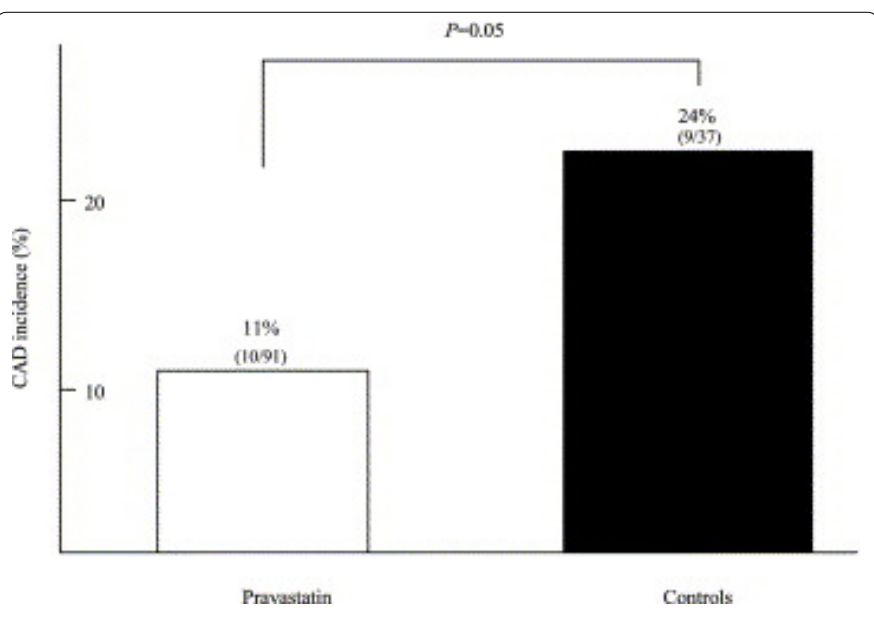

Figure 2: Five year incidence of coronary artery disease after heart transplantation in patients receiving pravastatin versus controls. Stojanovic et al. [18].

in survival and LDL-cholesterol between the two groups. There was a trend towards increased incidence of immunosuppression-related deaths in the simvastatin group. These effects may be due to differences in the pharmacokinetic profiles of the two drugs. Pravastatin is not metabolized by the cytochrome P450 3A4 isoenzyme, and is excreted largely unchanged, while simvastatin competes with cyclosporine and other drugs for metabolism by cytochrome CYP3A4 in the liver and small intestine[31].

Som et al. [32] conducted a systematic review of the role of statin therapy in graft vessel disease following cardiac transplantation and found consistent benefit in reducing CAV, whether the assessment was by angiography, IVUS or post-mortem. A survival benefit of statins was also noted, as was a decrease in the number of serious rejections. The post-transplantation timing of the introduction of statin therapy appeared important, and benefit was seen only in studies where statin therapy was initiated within 30 days of transplant. Furthermore, the rate of adverse events in published studies was low, with only one study showing a significantly higher incidence of myositis in statin-treated patients; while rhabdomyolysis and hepatic derangement were rare [32].

Among all the drugs investigated for the prevention of CAV, statins are the only group of drugs to be included as a class I recommendation for all heart transplant recipients by the International Society of Heart and Lung Transplantation (ISHLT)[33].

\section{Treatment of cytomegalovirus (CMV) infection}

The most common infection post-heart transplant, CMV, affects allograft endothelial function both directly (by affecting the nitric oxide pathway) and indirectly (by activating cytokines)[34].In a study using IVUS, the 1-year change in maximal intimal thickening (MIT) assessed at 1 and 12 months after heart transplantation was compared in groups of patients routinely assigned to a preemptive strategy for treatment of CMV (i.e. anti-viral drug administration restricted to patients with laboratory indicators of CMV infection) or receiving valganciclovir prophylaxis (irrespective of CMV infection). The 1-year increase in MIT was significantly lower in patients receiving prophylaxis compared with those managed preemptively, even after adjustment for metabolic risk factors, thus suggesting a role for CMV prophylaxis in CAV prevention [35]. In another study conducted in cardiac transplant recipients that were $\mathrm{CMV}$-antibody positive pre-transplant, a CMV-specific CD4 T-cell immune response in the first month after transplantation was associated with a reduction in CMV viral load, and was also associated with less transplant arteriopathy. Thus methods to enhance CMV-specific T-cell immunity may represent a therapeutic strategy for prevention of CAV [36]. Strategies to prevent CMV infection post-transplant are included in a class I recommendation for the prevention of CAV in ISHLT guidelines [33].

\section{Mycophenolatemofetil (MMF)}

In the MMF multicenter trial of 650 heart transplant patients at 28 centers, patients received either MMF or azathioprine (AZA) in addition to cyclosporine and corticosteroids. In the IVUS sub-study, patients receiving AZA compared to those on MMF had significantly more patients with first year MIT $\geq 0.3 \mathrm{~mm}$ and a significantly lower mean luminal area, thus suggesting a greater protective effect of MMF on preventing CAV [37]. This beneficial effect of MMF may be due to its suppression of both $\mathrm{T}$ - and B-lymphocyte function and reduction of arterial smooth muscle cell migration and proliferation[38]. Patients treated with MMF developed lower anti-vimentin antibody titers due to its effect on B lymphocytes, and this correlated with a lower incidence of CAV by IVUS [39]. In addition, MMF decreases activation of T-lymphocytes and HLA-DR-expressing NK cells [40]. MMF may also decrease systemic inflammatory activity in heart transplant patients as indicated by reduced levels of high-sensitivity C-reactive protein [41].

As with other immunosuppressive agents, MMF has a significant adverse effect profile, including diarrhea, cytopenias (anemia and leukopenia) and increased risk of bacterial, pneumocystis and CMV infections [42]. MMF is used as part of the standard immunosuppressive regimen along with calcineurin inhibitors and steroids as an antiproliferative agent [33].

\section{Proliferation Signal Inhibitors (PSI)}

Proliferation signal or mammalian target of rapamycin (mTOR) inhibitors were first identified in 1970 when rapamycin was isolated from a strain of Streptomyces hygroscopicus in soil at Easter Island (Rapa Nui). It was found to have antifungal and immunosuppressive properties. Two PSIs are currently available commercially:sirolimus (SRL) (previously known as rapamycin) and its derivative everolimus [43]. PSIs form a complex with the intracellular binding protein FKBP12 and inhibit the activity of mTOR, a serine/threonine kinase which functions within the cell as a transducer of information from growth factors and energy sensors [44]. This causes upregulation of thee cyclin- 
dependent kinase inhibitor $27^{\text {kip1 }}$, leading to inhibition of cell cycle progression at the G1 to $\mathrm{S}$ phase. Everolimus also blocks interleukin-2 (IL-2) and IL-15 driven proliferation of hematopoietic stem cells and vascular smooth muscle cells by inhibiting the activation of p70 S6 kinase $[45,46]$.

In a multi-center trial involving 634 patients, Eisen et al. [47]. showed decreased progression of intimal thickness by IVUS in patients treated with everolimus when compared with azathioprine at 12 months, when given along with cyclosporine and steroids [47]. In a study by Mancini et al. [48] cardiac transplant patients were randomly assigned to SRL or MMF/ azathioprine at their annual cardiac catheterization and followed annually thereafter. As compared to the control group, the SRL group showed significant reduction in theprimary end-point of death, need for angioplasty or bypass surgery, myocardial infarction, and a $>25 \%$ worsening of the catheterization score [48]. In de novo cardiac transplant recipients, Keogh et al. [49] compared SRL with azathioprine in a randomized open-label study and demonstrated that SRL-treated patients had significantly reduced intimal thickness and increased coronary lumen diameters by IVUS at 6 months and 2 years after transplantation when compared to azathioprine-treated patients [49]. Finally, in a recent multicenter randomized trial comparing MMF to everolimus after heart transplantation, the incidence of CAV (defined as an increase in MIT from baseline to month 12 of $>0.5 \mathrm{~mm}$ ) was $12.5 \%$ with everolimus versus $26.7 \%$ with MMF, and the difference remained significant irrespective of sex, age, diabetic status, donor disease, and across lipid categories [50].

In an observational study of 29 cardiac transplant recipients who were switched from calcineurin inhibitors (CNI) to SRL for renal dysfunction compared to 40 patients who were continued on CNI, an increase in the mean plaque volume and plaque index was seen with three-dimensional IVUS in patients receiving CNI after a year, but not in those who were switched to SRL [51]. This appears to be an attractive strategy, especially because CNIs stimulate fibrogenic growth factor and cause endothelial dysfunction [52]. However, concern exists regarding increase in acute rejection with CNI discontinuation [53]. Thus this strategy may only be applicable to patients who are further out from their transplant with no significant rejections, and have significant vasculopathy.

In addition to the effect of SRL on coronary anatomy, favorable effects on coronary physiology have also been demonstrated. In a small study of 27 patients, SRL therapy was associated with improved coronary artery physiology at the level of both the epicardial artery and the microvasculature, early after cardiac transplantation. There was a significant improvement in coronary flow reserve (CFR) and index of microcirculatory resistance (IMR) in the SRL group at 1 year after transplantation, but no change in the MMF group; while fractional flow reserve (FFR) declined in the MMF group but remained unchanged in the SRL group. The changes in epicardial coronary physiology may result from SRL's effect on plaque progression, while the improved microvascular function may be due to its effects on vascular remodeling and reactivity [54].

Interestingly, data analyzed from $>1000$ patients in 3 trials of de novo cardiac transplant recipients revealed that everolimus was associated with a lower incidence of CMV infection compared with azathioprine and MMF [55]. This may be an indirect mechanism of reduction of CAV by everolimus.

In an IVUS based study of early (from 3-6 weeks up to 1 year posttransplant) and late (from 1 to 5 years post-transplant) CAV, both everolimus and statins were associated with lower risk of developing markers of early CAV (increase in maximal intimal thickness). While statins were protective against late CAV development, everolimus lost its protective effect on CAV 1 to 5 years after transplant, suggesting that immune-mediated injury plays a greater role in development of CAV early after transplant, while metabolic factors predominate later [56]. This was further explored in other studies. Arora et al . [57] compared the morphologic progression of CAV using virtual histology (VH) in patients receiving maintenance immunosuppression with everolimus versus calcineurin inhibitor $(\mathrm{CNI})$. VH analysis revealed a significant increase in calcified and necrotic component among everolimus patients compared to controls. This increase was most prominent in patients who were $>5$ years post-heart transplant and was accompanied by a significant increase in levels of von Willebrand factor and vascular cell adhesion molecule [57] . In a similar study, compared with continued CNI therapy, SRL attenuated plaque progression in recipients with early conversion from CNI to SRL ( $<2$ years post-transplant), but contributed to increases in necrotic core and dense calcium volume in those with late conversion ( $>6$ years post-transplant) [58]. These studies suggest that the maximum benefit of PSIs lies in prevention rather than treatment of CAV.

Unfortunately, PSIs are associated with significant side-effects which may necessitate their discontinuation in many patients. In a large cohort of maintenance heart transplant recipients taking a PSI, $16 \%$ withdrew treatment in the first year, and 25\% had stopped PSI due to severe adverse events by the fourth year [59]. These adverse effects include but are not limited to [60], peripheral lymphedema [61], debilitating aphthous ulceration [62], wound dehiscence and impaired wound healing [63], hyperlipidemia [64], pneumonitisand anemia [66].

ISHLT guidelines give a class II a recommendation to substituting MMF or azathioprine with a PSI in patients with established CAV [33].

\section{Future Trends}

While several pharmacologic strategies are available for prevention of CAV, treatment strategies are limited. Focal coronary lesions can be treated percutaneously with stenting, but the ultimate treatment for diffuse CAV is re-transplantation which is neither the most feasible nor the safest option for most patients. Thus there is a need to expand the drug armamentarium for prevention and treatment of CAV. Some of the pharmacologic strategies explored in animal models are discussed below.

Memory $\mathrm{T}\left(\mathrm{T}_{\text {mem }}\right)$ cells are activated $\mathrm{T}$ cells that persist after the initial $\mathrm{T}$ cell response and provide continual immune protection to the host. Most infiltrating $\mathrm{T}$ cells in coronary arteries from patients with CAV express the phenotype of $\mathrm{T}_{\text {mem }}$ cells, suggesting that these cells may play an important role in the development of CAV [67]. OX40 (CD134) is a member of the tumor necrosis factor receptor (TNFR) superfamily.The OX40-OX40L signaling pathway has been found to play a key role in the survival and homeostasis of $\mathrm{T}_{\text {mem }}$ cells [68]. Wang et al. [69] demonstrated that CD40L deficient $\mathrm{T}_{\text {mem }}$ cells induce CAV in cardiac allografts, and blockage of the OX40 signaling pathway using anti-OX40L mAb reduces $\mathrm{T}_{\text {mem }}$ cell development and prevents CAV in a mouse cardiac transplantation model. Thus, the OX40 pathway may have a potential for prevention of CAV in cardiac transplant recipients [69].

In animal studies, cholesterol-rich nanoemulsions (LDE) resembling LDL combined with paclitaxel (LDE-paclitaxel) injected intravenously were demonstrated to reduce intimal width and reduce 
Citation: Shuchita Gupta MD (2014) Drugs for the Prevention and Treatment of Cardiac Allograft Vasculopathy. Cardiol Pharmacol 3: 123. doi:10.4172/2329-6607.1000123

Page 5 of 6

destruction of the media [70]. This may be a promising strategy for further exploration in clinical studies.

The oxidative stress associated with ischemia-reperfusion of cardiac allografts leads to cytokine production and expression of proinflammatory adhesion molecules. This is one of the most important alloantigen-independent factors associated with CAV and various strategies to ameliorate this oxidative stress have been studied. Antioxidants such as riboflavin [71] and superoxide dismutasemimetics [72] have been found to decrease oxidative stress and reduce the incidence of CAV in murine models of cardiac transplantation. Peroxisome proliferator-activated receptors $\gamma$ (PPAR- $\gamma$ ) receptor agonists such as pioglitazone also reduce oxidative stress and have been shown to reduce CAV [73].

Despite the evidence from animal studies, none of these pharmacologic strategies has made it to clinical trials. Hopefully some of these strategies will eventually be added to the clinical armamentarium for tackling CAV.

\section{Conclusion}

CAV remains a vexing problem in cardiac transplantation, with prevention being better than treatment. Drug therapy for CAV has modest efficacy and is limited by toxicity. Further research is needed in this area to tackle CAV and prolong graft survival.

\section{References}

1. Mehra MR, Crespo-Leiro MG, Dipchand A, Ensminger SM, Hiemann NE, et al. (2010) International Society for Heart and Lung Transplantation working formulation of a standardized nomenclature for cardiac allograft vasculopathy-2010. J Heart Lung Transplant 29: 717-727.

2. Lund LH, Edwards LB, Kucheryavaya AY, Dipchand Al, Benden C, et al. (2013) The Registry of the International Society for Heart and Lung Transplantation: Thirtieth Official Adult Heart Transplant Report--2013; focus theme: age. J Heart Lung Transplant 32: 951-964.

3. Day JD, Rayburn BK, Gaudin PB, Baldwin WM 3rd, Lowenstein CJ, et al. (1995) Cardiac allograft vasculopathy: the central pathogenetic role of ischemiainduced endothelial cell injury. J Heart Lung Transplant 14: S142-149.

4. Rose ML (2013) Role of anti-vimentin antibodies in allograft rejection. Hum Immunol 74: 1459-1462.

5. Pratschke J, Neuhaus P, Tullius SG (2005) What can be learned from braindeath models? Transpl Int 18: 15-21.

6. Rogers NJ, Lechler RI (2001) Allorecognition. Am J Transplant 1: 97-102.

7. Autieri MV (2003) Allograft-induced proliferation of vascular smooth muscle cells: potential targets for treating transplant vasculopathy. Curr Vasc Pharmacol 1: 1-9.

8. Vassalli G, Gallino A, Weis M, von Scheidt W, Kappenberger L, et al. (2003) Alloimmunity and nonimmunologic risk factors in cardiac allograft vasculopathy. Eur Heart J 24: 1180-1188.

9. Guddeti RR, Matsuo Y, Matsuzawa Y, Aoki T, Lennon RJ, et al. (2014) Ischemic cardiomyopathy is associated with coronary plaque progression and higher event rate in patients after cardiac transplantation. J Am Heart Assoc 3.

10. Vecchiati A, Tellatin S, Angelini A, lliceto S, Tona F (2014) Coronary microvasculopathy in heart transplantation: Consequences and therapeutic implications. World J Transplant 4: 93-101.

11. Hollenberg SM, Klein LW, Parrillo JE, Scherer M, Burns D, et al. (2001) Coronary endothelial dysfunction after heart transplantation predicts allograft vasculopathy and cardiac death. Circulation 104: 3091-3096.

12. Libby P, Lichtman AH, Hansson GK (2013) Immune effector mechanisms implicated in atherosclerosis: from mice to humans. Immunity 38: 1092-1104.

13. Mehra MR (2006) Contemporary concepts in prevention and treatment of cardiac allograft vasculopathy. Am J Transplant 6: 1248-1256.
14. Pober JS, Jane-wit D, Qin L, Tellides G (2014) Interacting mechanisms in the pathogenesis of cardiac allograft vasculopathy. Arterioscler Thromb Vasc Biol 34: 1609-1614.

15. Simper D, Wang S, Deb A, Holmes D, McGregor C, et al. (2003) Endothelial progenitor cells are decreased in blood of cardiac allograft patients with vasculopathy and endothelial cells of noncardiac origin are enriched in transplant atherosclerosis. Circulation 108:143-149.

16. Logani S, Saltzman HE, Kurnik P, Eisen HJ, Ledley GS (2011) Clinical utility of intravascular ultrasound in the assessment of coronary allograft vasculopathy: a review. J Interv Cardiol 24: 9-14.

17. Kobashigawa JA, Tobis JM, Starling RC, Tuzcu EM, Smith AL, et al. (2005) Multicenter intravascular ultrasound validation study among heart transplant recipients: outcomes after five years. J Am Coll Cardiol 45: 1532-1537.

18. Schroeder JS, Gao SZ, Alderman EL, Hunt SA, Johnstone I, et al. (1993) A preliminary study of diltiazem in the prevention of coronary artery disease in heart-transplant recipients. N Engl J Med 328: 164-170.

19. Schroeder JS, Gao SZ, Alderman EL, et al. (1994) Prevention of transplant accelerated coronary vascular disease with diltiazem [abstract]. J Am Coll Cardiol February Special Issue: 231A.

20. Mehra MR, Ventura HO, Smart FW, Collins TJ, Ramee SR, et al. (1995) An intravascular ultrasound study of the influence of angiotensin-converting enzyme inhibitors and calcium entry blockers on the development of cardiac allograft vasculopathy. Am J Cardiol 75: 853-854.

21. D’Ambrosio A, Giacomini E, Camponeschi B, Quintieri F (1998) Diltiazem modulates monokine production in human mixed lymphocyte culture. Transplantation 65: 1411-1413.

22. Goldstein JL, Brown MS (1990) Regulation of the mevalonate pathway. Nature 343: 425-430.

23. Moon SK, Cha BY, Kim CH (2004) ERK1/2 mediates TNF-alpha-induced matrix metalloproteinase- 9 expression in human vascular smooth muscle cells via the regulation of NF-kappaB and AP-1: Involvement of the ras dependent pathway. J Cell Physiol 198: 417-427.

24. Stein W, Schrepfer S, Itoh S, Kimura N, Velotta J, et al. (2011) Prevention of transplant coronary artery disease by prenylation inhibitors. J Heart Lung Transplant 30: 761-769.

25. Cutts JL, Scallen TJ, Watson J, Bankhurst AD (1989) Role of mevalonic acid in the regulation of natural killer cell cytotoxicity. J Cell Physiol 139: 550-557.

26. Kobashigawa JA, Katznelson S, Laks H, Johnson JA, Yeatman L, et al. (1995) Effect of pravastatin on outcomes after cardiac transplantation. N Engl J Med 333: 621-627.

27. Kapadia SR, Nissen SE, Ziada KM, Rincon G, Crowe TD, et al. (2001) Impact of lipid abnormalities in development and progression of transplant coronary disease: a serial intravascular ultrasound study. J Am Coll Cardiol 38: 206-213.

28. Stojanovic I, Vrtovec B, Radovancevic B, Radovancevic R, Yazdanbakhsh AP, et al. (2005) Survival, graft atherosclerosis, and rejection incidence in heart transplant recipients treated with statins: 5-year follow-up. J Heart Lung Transplant 24: 1235-1238.

29. Wenke K, Meiser B, Thiery J, Nagel D, von Scheidt W, et al. (1997) Simvastatin reduces graft vessel disease and mortality after heart transplantation: a fouryear randomized trial. Circulation 96: 1398-1402.

30. Wenke K, Meiser B, Thiery J, Nagel D, von Scheidt W, et al. (2003) Simvastatin initiated early after heart transplantation: 8-year prospective experience. Circulation 107: 93-97.

31. Christians U, Jacobsen W, Floren LC (1998) Metabolism and drug interactions of 3-hydroxy-3-methylglutaryl coenzyme A reductase inhibitors in transplant patients: are the statins mechanistically similar? Pharmacol Ther 80: 1-34.

32. Som R, Morris PJ, Knight SR (2014) Graft vessel disease following heart transplantation: a systematic review of the role of statin therapy. World J Surg 38: 2324-2334.

33. Costanzo MR, Dipchand A, Starling R, Anderson A, Chan M, et al. (2010) The International Society of Heart and Lung Transplantation Guidelines for the care of heart transplant recipients. J Heart Lung Transplant 29: 914-956.

34. Petrakopoulou P, Kübrich M, Pehlivanli S, Meiser B, Reichart B, et al. (2004) Cytomegalovirus infection in heart transplant recipients is associated with impaired endothelial function. Circulation 110: II207-212. 
Citation: Shuchita Gupta MD (2014) Drugs for the Prevention and Treatment of Cardiac Allograft Vasculopathy. Cardiol Pharmacol 3: 123. doi:10.4172/2329-6607.1000123

35. Potena L, Grigioni F, Magnani G, Lazzarotto T, Musuraca AC, et al. (2009) Prophylaxis versus preemptive anti-cytomegalovirus approach for prevention of allograft vasculopathy in heart transplant recipients. J Heart Lung Transplant 28: 461-467.

36. Tu W, Potena L, Stepick-Biek P, Liu L, Dionis KY, et al. (2006) T-cell immunity to subclinical cytomegalovirus infection reduces cardiac allograft disease. Circulation 114: 1608-1615.

37. Kobashigawa JA, Tobis JM, Mentzer RM, Valantine HA, Bourge RC, et al (2006) Mycophenolate mofetil reduces intimal thickness by intravascular ultrasound after heart transplant: reanalysis of the multicenter trial. Am J Transplant 6: 993-997.

38. Gregory CR, Huang X, Pratt RE, Dzau VJ, Shorthouse R, et al. (1995) Treatment with rapamycin and mycophenolic acid reduces arterial intimal thickening produced by mechanical injury and allows endothelial replacement. Transplantation 59: 655-661.

39. Rose ML, Smith J, Dureau G, Keogh A, Kobashigowa J (2002) Mycophenolate mofetil decreases antibody production after cardiac transplantation. J Heart Lung Transplant 21: 282-285

40. Weigel G, Griesmacher A, Karimi A, Zuckermann AO, Grimm M, et al. (2002) Effect of mycophenolate mofetil therapy on lymphocyte activation in heart transplant recipients. J Heart Lung Transplant 21: 1074-1079.

41. Pethig K, Heublein B, Wahlers T, Dannenberg O, Oppelt P, et al. (2004) Mycophenolate mofetil for secondary prevention of cardiac allograft vasculopathy: influence on inflammation and progression of intimal hyperplasia. J Heart Lung Transplant 23: 61-66.

42. Staatz CE, Tett SE (2014) Pharmacology and toxicology of mycophenolate in organ transplant recipients: an update. Arch Toxicol 88: 1351-1389.

43. Wiederrecht GJ, Sabers CJ, Brunn GJ, Martin MM, Dumont FJ, et al. (1995) Mechanism of action of rapamycin: new insights into the regulation of $\mathrm{G} 1$ phase progression in eukaryotic cells. Prog Cell Cycle Res 1: 53-71.

44. Sehgal SN (2003) Sirolimus: its discovery, biological properties, and mechanism of action. Transplant Proc 35: 7S-14S

45. Terada N, Lucas JJ, Szepesi A, Franklin RA, Domenico J, et al. (1993) Rapamycin blocks cell cycle progression of activated $T$ cells prior to events characteristic of the middle to late G1 phase of the cycle. J Cell Physiol 154 7-15.

46. Nashan B (2002) Early clinical experience with a novel rapamycin derivative. Ther Drug Monit 24: 53-58.

47. Eisen HJ, Tuzcu EM, Dorent R, Kobashigawa J, Mancini D, et al. (2003) Everolimus for the prevention of allograft rejection and vasculopathy in cardiactransplant recipients. N Engl J Med 349: 847-858.

48. Mancini D, Pinney S, Burkhoff D, LaManca J, Itescu S, et al. (2003) Use of rapamycin slows progression of cardiac transplantation vasculopathy. Circulation 108: 48-53.

49. Keogh A, Richardson M, Ruygrok P, Spratt P, Galbraith A, et al. (2004) Sirolimus in de novo heart transplant recipients reduces acute rejection and prevents coronary artery disease at two years: a randomized clinical trial. Circulation 110: 2694-2700.

50. Kobashigawa JA, Pauly DF, Starling RC, Randall CS, Howard E, et al. (2013) Cardiac allograft vasculopathy by intravascular ultrasound in heart transplan patients. JACC Heart Fail 1:389-399.

51. Raichlin E, Bae JH, Khalpey Z, Edwards BS, Kremers WK, et al. (2007) Conversion to sirolimus as primary immunosuppression attenuates the progression of allograft vasculopathy after cardiac transplantation. Circulation 116: 2726-2733.

52. Lungu AO, Jin ZG, Yamawaki H, Tanimoto T, Wong C, et al. (2004) Cyclosporin A inhibits flow-mediated activation of endothelial nitric-oxide synthase by altering cholesterol content in caveolae. J Biol Chem 279: 48794-48800.

53. Hunt J, Bedanova H, Starling R, Rabago G, Banner RN, et al. (2007) Premature termination of a prospective, open label, randomized, multicenter study of sirolimus to replace calcineurin inhibitos $(\mathrm{CNI})$ in a standard care regimen of $\mathrm{CNI}, \mathrm{MMF}$ and corticosteroids early after heart transplantation. J Heart Lung Transplant 26: S203

54. Sinha SS, Pham MX, Vagelos RH, Perlroth MG, Hunt SA, et al. (2008) Effect of rapamycin therapy on coronary artery physiology early after cardiac transplantation. Am Heart J 155: 889.
55. Kobashigawa J Ross H, Bara C, Delgado JF, Dengler T, et al. (2013) Everolimus is associated with a reduced incidence of cytomegalovirus infection following de novo cardiac transplantation. Transpl Infect Dis 15: 150-162.

56. Masetti M1, Potena L, Nardozza M, Prestinenzi P, Taglieri N, et al. (2013) Differential effect of everolimus on progression of early and late cardiac allograft vasculopathy in current clinical practice. Am J Transplant 13: 1217-1226.

57. Arora S, Erikstad I, Ueland T, Sigurdardottir V, Ekmehag B, et al. (2012) Virtua histology assessment of cardiac allograft vasculopathy following introduction of everolimus--results of a multicenter trial. Am J Transplant 12: 2700-2709.

58. Matsuo Y, Cassar A, Yoshino S, Flammer AJ, Li J, et al. (2013) Attenuation of cardiac allograft vasculopathy by sirolimus: Relationship to time interval after heart transplantation. J Heart Lung Transplant 32: 784-791.

59. Gonzalez-Vilchez F, Vazquez de Prada JA, Almenar L, Arizon Del Prado JM, Mirabet S, et al. (2012) Withdrawal of proliferation signal inhibitors due to adverse events in the maintenance phase of heart transplantation. $J$ Heart Lung Transplant 31: 288-295.

60. Kaplan B, Qazi Y, Wellen JR (2014) Strategies for the management of adverse events associated with mTOR inhibitors. Transplant Rev (Orlando) 28: 126 133.

61. Ribezzo M, Boffini M, Ricci D, Barbero C, Bonato R, et al. (2014) Incidence and treatment of lymphedema in heart transplant patients treated with everolimus. Transplant Proc 46: 2334-2338.

62. Campistol JM, de Fijter JW, Flechner SM, Langone A, Morelon E, et al. (2010) mTOR inhibitor-associated dermatologic and mucosal problems. Clin Transplant 24: 149-156.

63. Zuckermann A, Barten MJ (2011) Surgical wound complications after heart transplantation. Transpl Int 24: 627-636.

64. Tenderich G, Fuchs U, Zittermann A, Muckelbauer R, Berthold HK, et al. (2007) Comparison of sirolimus and everolimus in their effects on blood lipid profiles and haematological parameters in heart transplant recipients. Clin Transplant 21: $536-543$

65. Pham PT, Pham PC, Danovitch GM, Ross DJ, Gritsch HA, et al. (2004 Sirolimus-associated pulmonary toxicity. Transplantation 77: 1215-1220.

66. McDonald MA, Gustafsson F, Almasood A, Barth D, Ross HJ (2010) Sirolimus is associated with impaired hematopoiesis in heart transplant patients? A retrospective analysis. Transplant Proc 42: 2693-2696.

67. Brook MO, Wood KJ, Jones ND (2006) The impact of memory T cells on rejection and the induction of tolerance. Transplantation 82: 1-9.

68. Salek-Ardakani S, Croft M (2006) Regulation of CD4 T cell memory by OX40 (CD134). Vaccine 24: 872-883.

69. Wang H, Zhang Z, Tian W, Liu T, Han H, et al. (2014) Memory T Cells Mediate Cardiac Allograft Vasculopathy and are Inactivated by Anti-OX40L Monoclonal Antibody. Cardiovasc Drugs Ther 28: 115-122.

70. Lourenço-Filho DD, Maranhão RC, Méndez-Contreras CA, Tavares ER, Freitas FR, et al. (2011) An artificial nanoemulsion carrying paclitaxel decreases the transplant heart vascular disease: a study in a rabbit graft model. $\mathrm{J}$ Thorac Cardiovasc Surg 141:1522-1528.

71. Hasegawa T, Iwanaga K, Hultquist DE, Liao $\mathrm{H}$, Visovatti $\mathrm{SH}$, et al. (2009) Suppression of nitrosative and oxidative stress to reduce cardiac allograft vasculopathy. Am J Physiol Heart Circ Physiol 296: H1007-1016.

72. Murata S, Miniati DN, Kown MH, Koransky ML, Lijkwan MA, et al. (2004) Superoxide dismutase mimetic m40401 reduces ischemia-reperfusion injury and graft coronary artery disease in rodent cardiac allografts. Transplantation 78: 1166-1171.

73. Hasegawa T, Okada K, Okita Y, Pinsky DJ (2011) Antioxidant properties of pioglitazone limit nicotinamide adenine dinucleotide phosphate hydrogen oxidase and augment superoxide dismutase activity in cardiac allotransplantation. J Heart Lung Transplant 30:1186-1196. 